\section{Santa, Can You Hear Me?}

\author{
Dear Santa,
}

I hope my letter finds you in good health. I suspect that, as usual, you are pretty busy right now. I can't even imagine how your elves keep up with everyone's requests. I always thought they did a fantastic job making dolls and teddy bears and red wagons and such. But now all the kids want iPads, wireless earbuds, and smart phones. It's a whole new world, right?

Now, I feel a little awkward about bringing this up, but I must point out that you haven't brought me anything I've asked for in the past few years. I'm confused about this, because I have really tried to be a very good girl. Of course, I did use a bad word when my flight was canceled last week. But I was pretty tired that day, and I was going to an important meeting. Still, you're right; it wasn't nice, and I won't do it again.

Anyway, I thought I would give these requests another try. Like most oncologists, I'm an optimist! So here it goes: I just want 3 little things.

First, it would be great if you could provide drugs that cost less for our patients. Drug expenses are a big problem that no one seems to be able to do anything about. Maybe your elves could make them cheaper. Just a thought.

Second, we have a number of drugs that do the same things. For example, many checkpoint inhibitors, antiangiogenesis agents, and biosimilars are supposed to do exactly what an earlier version of the drug did. If you could just figure out the best ones in each category and put them in my stocking, I would really appreciate it.

Finally, these authorizations for treatment and procedures are killing me. This paperwork is a big waste of time and causes unnecessary delays for patients, especially since I eventually get just about whatever I ask for. If you could just send a directive to insurers to skip this and instead do a periodic audit to make sure we are all toeing the line, it would save both them and us time and money.

Before I sign off, I hope you don't mind if I offer you a little advice. Last year, I suggested you lay off those tasty cookies coming from Mrs. Claus' kitchen, but some recent pictures suggest that you didn't cut your carbs much. This is serious and I really mean it, Santa. Being overweight is just not good for you, and you might get cancer. And if you did, you might find that the North Pole Oncology Group is out of your network. But let's not go there.

In closing, thank you in advance for considering my Christmas wishes. I wish you, Mrs. Claus, and those talented elves much success and prosperity in the coming New Year.

$$
\begin{aligned}
& \text { Happy Holidays, } \\
& \text { Margazet }
\end{aligned}
$$
JNCCN@nccn.org or log into www.editorialmanager.com/JNCCN.

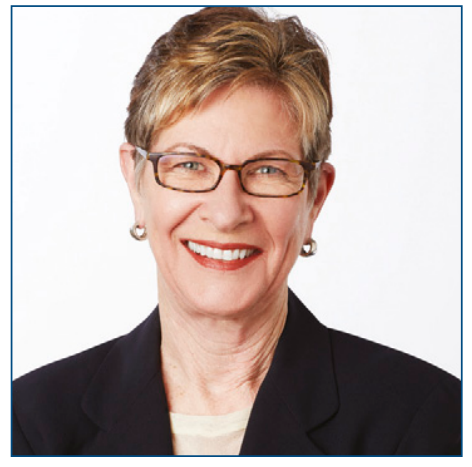

MARGARET TEMPERO, MD

Margaret Tempero, MD, is a Professor of Medicine and Director of the UCSF Pancreas Center and editor-in-chief of JNCCN. Her research career has focused on pancreatic ductal adenocarcinoma, especially in the area of investigational therapeutics. Dr. Tempero has served on the ASCO Board of Directors and as ASCO President. She currently serves on the ASCO Conquer Cancer Foundation Board. She codirected the AACR/ASCO Methods in Clinical Cancer Research and taught this course and similar courses in Europe and Australia. She was founding Chair of the $\mathrm{NCl}$ Clinical Oncology Study Section and served as a member and Chair of the $\mathrm{NCl}$ Board of Scientific Counselors Subcommittee A. She is a member of the Scientific Steering Committee and Chair of the Clinical and Translational Study Section for the Cancer Prevention \& Research Institute of Texas. She is or has been on the Scientific Advisory Boards of the Lustgarten Foundation, the Pancreatic Cancer Action Network, the V Foundation, The Alberta Canada Cancer Board, and the EORTC. She served as a member of the Oncology Drug Advisory Committee for the FDA. She has served as Deputy Director and Interim Director for the UNMC Eppley Cancer Center. She is Chief Emeritus of the Division of Medical Oncology at UCSF. She served as the founding Deputy Director and was later Director of Research Programs at the UCSF Helen Diller Family Comprehensive Cancer Center.

doi: $10.6004 /$ jnccn.2019.0060

The ideas and viewpoints expressed in this editorial are those of the author and do not necessarily represent any policy, position, or program of NCCN. 